\title{
An outbreak of epidemic keratoconjunctivitis caused by adenovirus type 37
}

\author{
S. CURTIS, G. W. G. WILKINSON* and D. WESTMORELAND
}

Department of Medical Microbiology and Public Health Laboratory, University Hospital of Wales, Heath Park Cardiff CF4 4XW and ${ }^{*}$ Department of Medicine, Tenovus Building, University of Wales College of Medicine, Heath Park, Cardiff CF4 4XX

\begin{abstract}
An outbreak of acute keratoconjunctivitis in an ophthalmology department affected 15 patients and seven members of staff and necessitated temporary closure of the unit. Adenovirus (Ad) was isolated from eye swabs taken during the outbreak, but typing of the isolates by virus neutralisation assay proved unsatisfactory, wrongly assigning the isolate to serotype 10. A robust and rapid method for preparing microgram amounts of Ad DNA from infected cells was devised and used as the basis of a non-radioactive method for routine genotyping of adenovirus clinical isolates. All isolates associated with the outbreak, and one from a patient presenting at a nearby hospital during the outbreak, were found to have restriction endonuclease digestion patterns characteristic of Ad 37.
\end{abstract}

\section{Introduction}

Adenovirus (Ad) infections are a major cause of eye disease as a result of their association with the two clinical syndromes: pharyngoconjunctival fever and epidemic keratoconjunctivitis. The incubation period of pharyngoconjunctival fever is c. 8 days and produces ocular hyperaemia, watery discharge and follicle formation, often accompanied by fever and pharyngitis and pre-auricular lymphadenopathy. Epidemic keratoconjunctivitis can cause severe eye disease which presents as oedema of the eyelids and conjunctivae and subconjunctival haemorrhage. It differs from other forms of Ad conjunctivitis in that the cornea is involved, subepithelial corneal opacities develop and these may persist, threatening the patient's sight [1].

The vast majority of Ad isolates from the eye grow well in tissue culture and initial identification can be made readily with an Ad-specific monoclonal antibody (MAb) in an immunofluorescence assay. While the accurate typing of Ad isolates can be problematic, it can also be of considerable clinical and epidemiological value. Typing becomes particularly important in an outbreak to identify cases and monitor the success of control measures. An outbreak of epidemic

Received 23 Jan. 1997; revised version received 20 May 1997; accepted 28 May 1997.

Corresponding author: Dr G. W. G. Wilkinson. keratoconjunctivitis affecting seven members of staff and 15 patients in a local ophthalmology clinic necessitated the temporary closure of the unit. Accurate typing of virus isolates was considered essential for efficient management of this outbreak.

Ad isolates are routinely typed by neutralisation assay, but this method has several disadvantages. Typing by neutralisation assay is dependent on the use of qualityassured antisera against all Ad serotypes. Currently, in excess of 47 Ad serotypes have been identified $[1,2]$. Antisera currently available were prepared prior to the identification of some Ad strains currently circulating and thus these serotypes will not be identified. The method is time consuming and labour intensive, and cross-neutralisation may result in isolates being wrongly identified [3]. Ad isolates associated with the outbreak in the ophthalmology clinic were identified as serotype 10 by neutralisation assay. However, the clinical features of the outbreak were typical of epidemic keratoconjunctivitis, which tends to be most frequently associated with serotypes 8,19 and 37 [4-6]. A more definitive technique was deemed to be required for the analysis of isolates cultured from the outbreak.

Restriction endonuclease analysis (REA) of Ad DNA can be used to genotype isolates accurately by comparing DNA restriction patterns against known profiles for a range of different enzymes [7, 8]. REA has the capacity to type isolates for which neutralising antisera are not readily available, permit 
the identification of novel genotypes and differentiate between serologically indistinguishable strains [7]. Some methods of REA are technically demanding, time consuming or may require the use of radioactive isotopes to identify viral DNA. These constraints have prohibited wide use of REA in diagnostic virology. This paper describes a rapid and straightforward method for extraction of Ad DNA in a routine clinical virology laboratory. Analysis of the Ad DNA by means of restriction endonuclease patterns and direct staining with ethidium bromide was used to type Ad isolates from an outbreak of epidemic keratoconjunctivitis.

\section{Materials and methods}

For the culture of virus, eye swabs were taken from individuals with keratoconjunctivitis and immediately immersed in viral transport media. The sample was then inoculated on to HEp2 cells, human fetal foreskin fibroblasts, MRC5 cells and HEL cells. The culture tubes were placed in roller drums and incubated for up to 14 days at $37^{\circ} \mathrm{C}$. Cultures exhibiting a CPE were tested for $\mathrm{Ad}$ infection by immunofluorescence with a group-specific MAb to Ad (DAKO Diagnostics, Cambridge). Positive cultures were then further passed into fresh HEp2 cells before being typed by neutralisation assay. Prototype Ad type 10 and 37 (obtained from Laboratory of Microbiological Reagents, CPHL, 61 Colindale Ave, London) were grown in HEp2 cells and stored at $-80^{\circ} \mathrm{C}$.

\section{Neutralisation assay}

Antisera to the more common Ad types were used (types 1, 2, 3, 4, 5, 6, 7, 11 and 14) in a first screen and then additional antisera $(8,10,15,16,17,18,19$ and 20) were used if no identification was made initially. Virus cultures $(100 \mu \mathrm{l})$ were mixed with $100 \mu \mathrm{l}$ of type-specific antiserum for $1 \mathrm{~h}$ at $20^{\circ} \mathrm{C}$, after which the serum/virus mixture was inoculated into $\mathrm{HEp} 2$ cells. Cultures were incubated at $37^{\circ} \mathrm{C}$ and viewed daily until a positive culture (without antibody) showed CPE. The Ad type was determined by the antiserum which completely inhibited viral growth.

\section{Rapid purification of Ad DNA}

Sub-confluent HEp2 cells in a $75-\mathrm{cm}^{2}$ flask were inoculated with Ad and incubated at $37^{\circ} \mathrm{C}$ until CPE was extensive. The monolayer was dislodged with a cell scraper and recovered by centrifugation. Cells were washed once with phosphate-buffered saline, resuspended in $1 \mathrm{~mm}$ EDTA, $10 \mathrm{mM}$ Tris, $\mathrm{pH} 7.5$, (TE) buffer and extracted once with an equal volume of the fluorocarbon ArkloneP (Basic Chemical Company, High Wycombe) $[9,10]$. The extract was centrifuged for $5 \mathrm{~min}$ at $1000 \mathrm{~g}$ and the aqueous (top) phase was transferred to a fresh tube where SDS was added to $1 \%$ and proteinase $\mathrm{K}$ to $200 \mu \mathrm{g} / \mathrm{ml}$. The reaction was incubated at $37^{\circ} \mathrm{C}$ for $1 \mathrm{~h}$ before being extracted twice with an equal volume of phenol:chloroform $(1: 1 \mathrm{v} / \mathrm{v})$ and once with an equal volume of chloroform. To precipitate Ad DNA, sodium acetate ( $\mathrm{pH}$ 4.8) was added to a final concentraiton of $0.3 \mathrm{M}$ and the solution mixed with 2 vol of ethanol and stored overnight at $-20^{\circ} \mathrm{C}$. DNA was recovered by centrifugation (normally $3 \times 1.5-\mathrm{ml}$ tubes for each sample) for $5 \mathrm{~min}$ in a Sanyo microfuge. The small white or clear precipitate was air dried $\left(37^{\circ} \mathrm{C}\right)$ and resuspended in $100 \mu 1$ of TE buffer. Yields varied but typically sufficient DNA sample was produced to permit analysis in 10 restriction endonuclease digests.

\section{Restriction endonuclease digestion and electrophoresis}

Restriction endonuclease digests and agarose gel electrophoresis were performed by standard techniques [11]. RNAase A $(0.1 \mu \mathrm{g}$; Sigma) was included in all the restriction endonuclease digests and samples were analysed on an agarose $0.7 \%$ mini-gel. Restriction endonucleases and the mol.wt marker (BstEII digested $\lambda$ DNA) were obtained from New England Biolabs (Hitchin).

\section{Results}

A series of 22 Ad isolates was obtained over a period of 4 weeks of the outbreak in the ophthalmology unit. The infectious agent was identified as being an adenovirus by immunofluorescence on infected cell cultures. All the Ad isolates were then characterised by a standardised neutralisation assay and assigned by this method to serotype 10 . Further analysis of the isolates by REA was initiated. Independent isolates cultured from eye swabs of two patients with conjunctivitis presenting at a different hospital which had also been assigned to serotype 10 by the neutralisation assay and one isolate assigned to serotype 3 were also examined in parallel.

Ad DNA was prepared both from isolates associated with the outbreak and appropriate controls according to a standardised protocol and digested with a range of restriction endonucleases. The digest patterns obtained with Bam HI and XhoI are illustrated in Figs. $1 \mathrm{a}$ and $\mathrm{b}$. Identical cleavage patterns were obtained with the six representative isolates from the outbreak analysed by cleavage with Bam HI and the five isolates examined with XhoI. These results indicated that a single Ad genotype was associated with the outbreak. Two independent clinical isolates, also assigned as serotype 10 , were also examined in this experiment. Interestingly, one of these isolates (B in Figs. 1a and b) had a restriction endonuclease cleavage profile identical to that of the isolates associated with the outbreak, while the second was 
a

\section{kb}
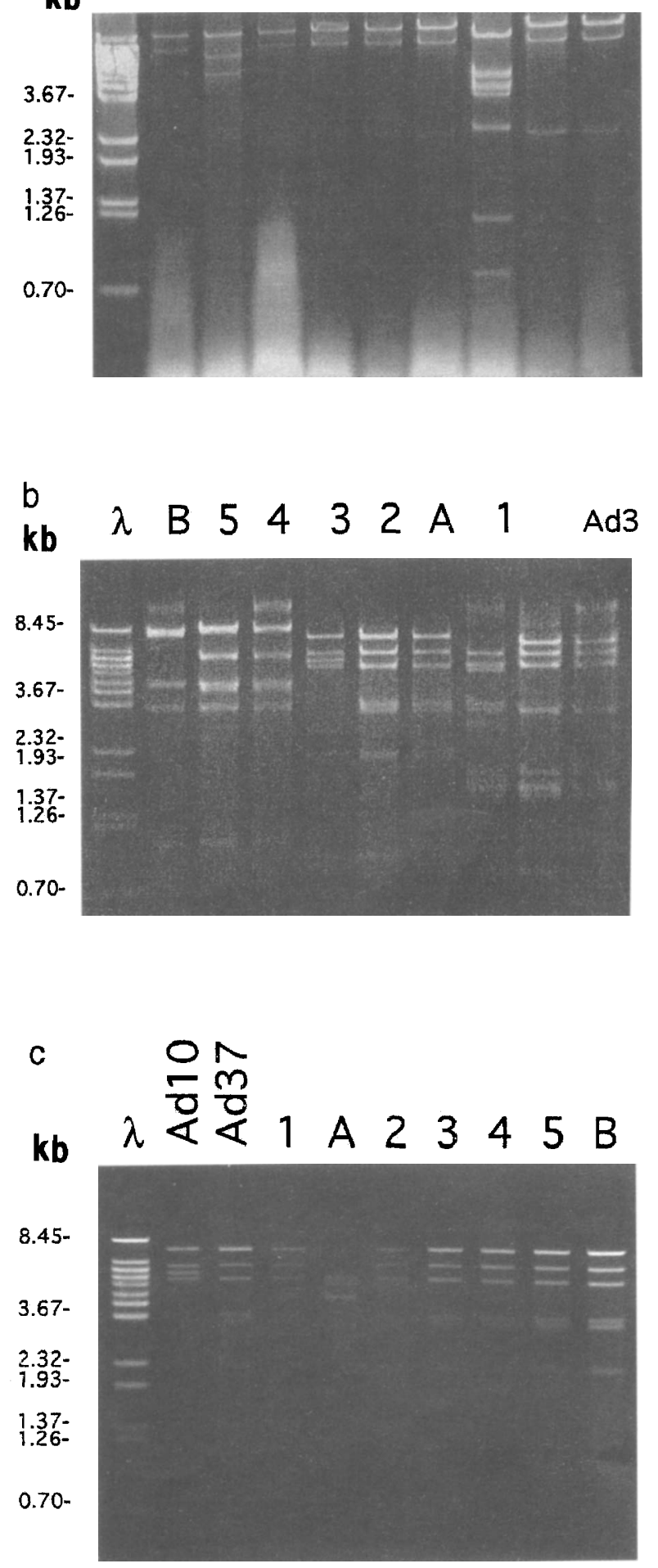

Fig. 1. Restriction endonuclease digest of Ad DNA. (a) Bam HI digests of Ad DNA purified from clinical isolates associated with the ophthalmology clinic outbreak (labelled 1-6), two independent clinical isolates (labelled $\mathrm{A}$ and $\mathrm{B}$ ) and a clinical isolate identified as belonging to Ad serotype 3. (b) Xhol digests of Ad DNA purified from clinical isolates $1-5$ (numbered as above), clinical isolates $\mathrm{A}$ and $\mathrm{B}$ and the $\mathrm{Ad} 3$ clinical isolate. (c) HindIII digests of Ad DNA purified from clinical isolates 1-5 (numbered as above), clinical isolates $\mathrm{A}$ and $\mathrm{B}$, and for Ad10 and Ad37 reference strains. The mol.wt standard was a BstEII digest of $\lambda$ virus DNA, fragment sizes are given in $\mathrm{kb}$. clearly different ( $\mathrm{A}$ in Figs. $1 \mathrm{a}$ and $\mathrm{b}$ ). $\mathrm{Ad} 3$ is a common Ad serotype associated with conjunctivitis [12]. The clinical isolate assigned to serotype 3 by neutralisation assay was also digested with Bam $\mathrm{H} 1$ and Xho1 and showed a different pattern from the outbreak strains.

A comparison between the cleavage patterns obtained in Figs. 1a and b and a published catalogue of Ad DNA digests indicated that the restriction endonuclease patterns for the outbreak strains were distinct from Ad10 but similar to that of $\operatorname{Ad} 37$. One isolate from the nearby hospital also matched the profile for Ad37. To test the hypothesis that the outbreak of epidemic keratoconjunctivitis was caused by $\mathrm{Ad} 37$, DNA samples representative of the outbreak and DNA from reference Ad10 and Ad37 strains, provided by the Laboratory for Microbiological Reagents, were compared. The HindIII cleavage pattern of $\mathrm{Ad} 37$, but not of Ad10, was identical to that of the clinical isolates associated with the outbreak and one of the sporadic cases (B) (Fig. 1c). Interestingly, the second independent isolate (A) previously assigned as serotype 10 was clearly distinct from both the Ad10 and Ad37 reference strains (Fig. 1c).

To test further the assignment of the outbreak strain as Ad37, BglII, BstEII and HindIII digests were performed in parallel on the Ad37 and Ad10 reference strains and a representative isolate from the outbreak. The Ad strain associated with the outbreak had the same restriction endonuclease pattern with all three enzymes as $\operatorname{Ad} 37$ and was clearly distinct from Ad10 with all three enzymes (Fig. 2).

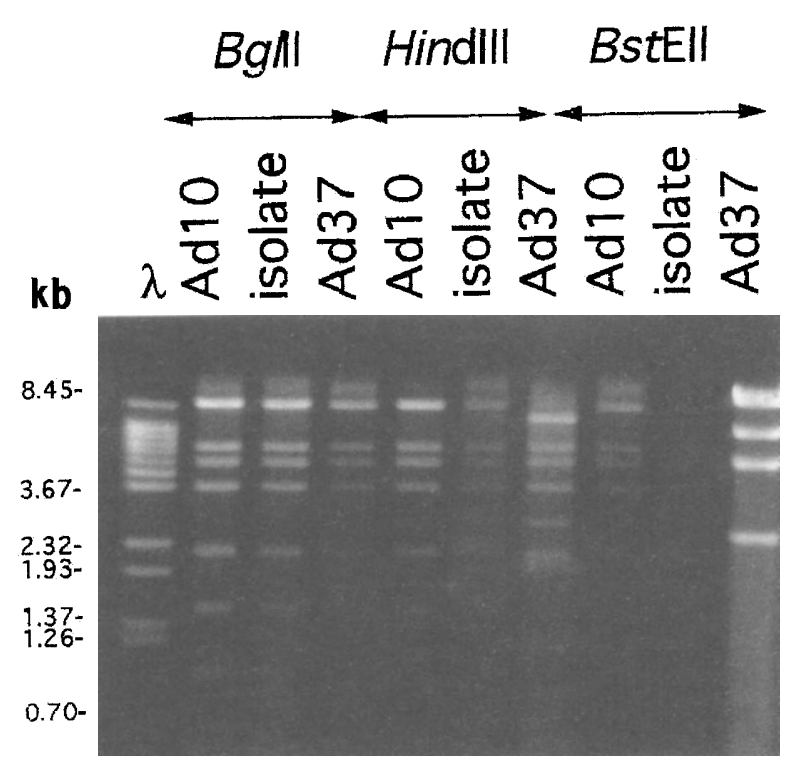

Fig. 2. DNA from a representative isolate from the clinical outbreak and the $\operatorname{Ad} 10$ and $\operatorname{Ad} 37$ reference strains were digested with the restriction endonucleases $B g l \mathrm{II}$, HindIII and BstEII. The mol.wt standard was a Bst $\mathrm{E} 11$ digest of $\lambda$ virus DNA. 


\section{Discussion}

Serotyping is dependent on measuring the relative ability of hyperimmune reference sera to neutralise virus infection by means of binding to a limited number of epitopes located on the hexon (predominantly), fibre and penton-base proteins of virus particles [13]. Conventional serotyping depends on both the quality and availability of appropriate reference sera and samples an extremely small portion of the virus genome, i.e., the coding sequence for a limited number of neutralisation epitopes. Antisera currently in use were prepared before the identification of new Ad strains; indeed, reference antiserum to Ad37 was not available to the routine diagnostic laboratory during this study. Ad37 is a major cause of keratoconjunctivitis and the misidentification in this outbreak highlights the limitations of virus neutralisation in routine typing [14].

This paper describes a rapid, straightforward method for preparing Ad DNA that can be used for typing Ad isolates by restriction endonuclease digestion and can be used in a routine diagnostic virology laboratory either for typing common isolates or analysing outbreaks. Genotyping is intuitively more satisfactory in that it can use a range of different restriction endonucleases to sample across the entire virus genome in a predictable and defined fashion. REA of DNA can not only differentiate all known Ad serotypes, but also may be used to discriminate genome types within a serotype [15].

The Ad isolates associated with the outbreak were provisionally assigned to serotype 10 . However, REA demonstrated that the patterns of the outbreak strains clearly differed from that of a reference Ad10 pattern, but matched the reference Ad37 pattern. Furthermore, REA of two independent clinical isolates, previously identified as serotype 10 by serology, demonstrated one to be type 37 (and indistinguishable from the outbreak strain). Restriction enzyme profiles with two enzymes point to the second independent clinical isolate being a type 27 adenovirus. Ad27 is relatively rare [16] and a screening serum for this serotype was not available for the neutralisation assay.

In conclusion, the present study demonstrated the usefulness of rapid REA typing in a routine diagnostic virology laboratory during an outbreak of epidemic keratoconjunctivitis in a hospital. During the outbreak the same strain (Ad37) was detected in a sample presenting to a hospital some distance away, where there was not an outbreak. We suggest that the outbreak occurred following introduction into the ophthalmology department of a strain from the community and inadequate infection control measures within the hospital clinic.

We thank Mrs Denise Parton and Mrs Jean Tamplin for technical assistance and Mrs Allison Keenor for typing the manuscript.

\section{References}

1. Sharp IR, Wadell G. Adenoviruses. In: Zukerman AJ, Banatvala JE, Pattison JR (eds) Principles and practice of clinical virology, 3rd edn. Chichester, John Wiley and Sons. 1994: 287-308

2. Horwitz MS. Adenoviruses. In: Fields BN, Knipe DM, Howley PM (eds) Fields Virology, 3rd edn. Philadelphia, LippincottRaven. 1996: 2045-2074

3. Fife KH, Ashley R, Sheilds AF, Salter D, Meyers JD, Corey L. Comparison of neutralization and DNA restriction enzyme methods for typing clinical isolates of human adenovirus. $J$ Clin Microbiol 1985; 22: 95-100.

4. McMinn PC, Stewart J, Burrell CJ. A community outbreak of epidemic keratoconjunctivitis in central Australia due to adenovirus type 8 . J Infect Dis 1991; 164: 1113-1138.

5. Kemp MC, Hierholzer JC, Cabradilla CP, Obijesti JF. The changing etiology of epidemic keratoconjunctivitis: antigenic and restriction enzyme analyses of adenovirus types 19 and 37 isolated over a 10-year period. $J$ Infect Dis 1983; 148: 24-33.

6. Takeuchi R, Monura Y, Kojima M, Uchior E, Kobayashi N, Matumoto M. A nosocomial outbreak of epidemic keratoconjunctivitis due to adenovirus type 37. Microbiol Immunol 1990 34: 749-754.

7. Adrian TH, Wadell G, Hierholzer JC, Wigand R. DNA restriction analysis of adenovirus prototypes 1 to 41 . Arch Virol 1986; 91: 277-290.

8. Adrian TH, Wagand R. Restriction size mapping of subgenus D adenovirus, prototypes $42-47$, intermediate and atypical strains. Int J Med Microbiol 1991; 275: 107-119.

9. Precious B, Russell WC. Growth, purification and titration of adenoviruses. In: Mahy BWJ (ed) Virology: a practical approach. Oxford, IRL Press. 1985: 193-205.

10. Graham FL, Prevec L. Manipulation of adenovirus vectors. In: Murray EJ (ed) Methods in molecular biology, no. 7. Clifton, NJ, Humana Press. 1991: 109-128.

11. Sambrook J, Fritsch EF, Maniatis T. Molecular cloning, a laboratory manual, 2nd edn. Cold Spring Harbor, NY, Cold Spring Harbor Laboratory Press. 1989

12. Darougar S, Grey RH, Thaker U, McSwiggan DA. Clinical and epidemiological features of adenovirus keratoconjunctivitis in London. Br J Ophthalmol 1983; 67: 1-7.

13. Norrby E, Wadell G. Immunological relationships between hexons of certain human adenoviruses. $J$ Virol 1969; 4 : 663-670.

14. Harding SP, Mutton KJ, van der Avoort, HGAM, Wermenbol AG. An epidemic of keratoconjunctivitis due to adenovirus type 37. Eye 1988; 2: 314-317.

15. Wadell G. Molecular epidemiology of human adenoviruses. In Doerfler W (ed) The molecular biology of adenoviruses 2. 30 years of adenovirus research 1953-1983 (Current Topics in Microbiology and Immunology 110). Berlin, Springer-Verlag. 1984: $191-220$.

16. Hierholzer JC. Adenoviruses. In: Schmidt NJ, Emmons RW (eds) Diagnostic procedures for viral, rickettsial and chlamydial infections, 6th edn. Washington, DC, American Public Health Association. 1995: 219-252. 